\title{
CATÁSTROFE! INTERAÇÕES MUSICAIS NA EDUCAÇÃO INFANTIL: EXPERIÊNCIAS COM ESTUDANTES DE PEDAGOGIA E LIVROS DIDÁTICOS
}

\author{
Catastrophe! Music interactions in childhood education: \\ experiences with pedagogy students and textbooks
}

\author{
LUCIANA REQUIÃO \\ Universidade Federal Fluminense \\ lucianarequiao@id.uff.br
}

\begin{abstract}
Resumo: Este estudo é parte da pesquisa Arte, educação musical e a formação do pedagogo, que busca compreender e discutir o papel da arte na educação infantil e as possibilidades de interação do pedagogo nesse contexto. Nele analisamos de que forma o professor- pedagogo em formação se apropria de livros didáticos musicais destinados ao professor não especialista. Por meio de intervenções em turmas da educação infantil, constatou-se que os materiais não são suficientemente legiveis. As atividades propostas foram limitadas por uma compreensão bastante superficial do que pode ser um trabalho com música em sala de aula. A tendência é um apego exagerado aos procedimentos descritos nos livros e pouca liberdade para se arriscar em novas interpretações e interações não previstas. Nesse sentido, os estudantes de pedagogia não foram capazes de, naquele momento, lidar com o incerto e o imprevisto. Mais do que buscar capacitar os futuros professores no manejo com os elementos musicais, o nosso trabalho versa sobre como conjugar esses saberes com a dinâmica de ensino necessária às especificidades do campo de atuação do professor pedagogo, o que implica um trabalho interdisciplinar.
\end{abstract}

Palavras-chave: Educação musical. Educação infantil. Livro didático.

\begin{abstract}
This study is part of the research Art, music education and teacher education that is aimed at understanding and discussing the role of art in childhood education and the possibilities of interaction of the teacher in this context. In it we analyze how the teacher who is studying pedagogy deals with music textbooks for non-expert teachers. During interventions in classes of childhood education, we found that the materials are not sufficiently legible. The activities suggested were limited by an extremely superficial understanding of what can be done with music in class. The tendency is an exaggerated attachment to the procedures described in the books and limited freedom to try new interpretations and unexpected interactions. In this sense, pedagogy students were not capable of dealing with uncertainty and unexpected events at that time. In addition to trying to instruct new teachers in managing the elements of music, our work discusses how to combine this knowledge with the teaching dynamics necessary for the specificities of the field of education, which implies an interdisciplinary work.
\end{abstract}

Keywords: Music education. Childhood education. Textbooks. 


\section{APRESENTAÇÃO}

Este estudo é parte da pesquisa Arte, educação musical e a formação do pedagogo, que teve início no ano de 2016, junto ao Grupo de Estudos em Cultura, Trabalho e Educação (GECULTE) da Universidade Federal Fluminense (UFF). ${ }^{1}$ Pretendemos, como objetivo geral, compreender e discutir o papel da arte na educação infantil e como a formação acadêmica e a atuação de professores-pedagogos podem nela favorecer o desenvolvimento da linguagem musical. Entendemos a arte como uma área de conhecimento cuja ênfase do fazer artístico se concentra tanto no processo quanto no produto ${ }^{2} \mathrm{e}$ que, particularmente no âmbito da educação infantil, deve se dar de forma interdisciplinar, articulada às outras áreas de conhecimento necessárias à formação do pedagogo. A pesquisa em questão está inserida no contexto da formação inicial e continuada de professores não especialistas na área da música e busca conhecer, discutir, analisar e compreender o papel da arte e da música, em particular, na formação e na atuação profissional do pedagogo.

Nos últimos dez anos, vivenciamos um intenso debate sobre a música na escola que incluiu uma discussão sobre a formação de professores especialistas e não especialistas. Como um dos marcos desse período, podemos citar a campanha Quero educação musical na escola, que, segundo Pereira (2010, p. v), foi "um movimento setorial da sociedade civil organizada com características sem precedentes tornado possivel devido às condições sociopoliticas contemporâneas a partir do ano 2008, quando foi promulgada a Lei $11.769{ }^{3}{ }^{3}$ Desde então, muitas publicações foram produzidas com o intuito de oferecer subsídios ao trabalho com música nas escolas, tanto ao professor especialista quanto ao não especialista. Esse é o caso, por exemplo, da revista Música na Educação Básica, publicada pela Associação Brasileira de Educação Musical (ABEM), que teve o seu primeiro número editado em 2009. ${ }^{4}$

$\mathrm{Na}$ atual fase de nossos estudos, analisamos materiais didáticos como esse. O ponto central de nossa análise é observar se este material é legivel ao professor que não teve uma formação específica na área da música. Partimos de estudos como os de Bellochio e Garbosa (2014) e de Figueiredo (2017), ${ }^{5}$ e de pesquisas que realizamos nos últimos anos (REQUIÃO, 2013a e 2017) que

\footnotetext{
${ }^{1}$ www.culturatrabalhoedu.uff.br

2 Tal concepção de ensino de arte se aproxima do que Silva e Araújo (2007) apresentam como uma tendência pós-modernista: "Ao contrário da concepção de ensino como técnica - que valoriza o produto artístico em detrimento do processo - e da concepção de ensino de arte como expressão - que supervaloriza o processo, dando pouca importância ao produto estético -, a concepção de arte como conhecimento vem buscando a valorização tanto do produto artístico quanto dos processos desencadeados no ensino de arte" (p. 15).

${ }^{3}$ Sobre o processo de aprovação da Lei 11.769 (Brasil, 2008) ver Figueiredo (2010).

4 Atualmente a revista conta com oito volumes, sendo o último publicado em 2017, disponíveis em: <http://www.abemeducacaomusical.com.br/revista_meb.asp>. Acesso em: 4 jan. 2018.

${ }^{5}$ Venho acompanhando o trabalho desses autores que tratam da relação entre a educação musical e a formação do pedagogo. Cito aqui apenas alguns dos mais recentes.
} 
mostram a insuficiência da formação musical na trajetória acadêmica de professores-pedagogos regentes de turma, também conhecidos como unidocentes ou generalistas. Estes são os professores que aqui chamamos de não especialistas na área da música. Pretendemos verificar em que medida o professor-pedagogo pode se apropriar, transformar e/ou adaptar os materiais didáticos disponiveis para o ensino da música na educação básica, em especial os destinados à educação infantil.

Nesse primeiro momento, os materiais selecionados por nossa pesquisa tiveram como principal característica o fato de serem publicações no formato "livro impresso" e explicitamente destinados ao professor não especialista em música. Considerando que o termo "material didático" pode se referir a uma ampla gama de materiais, caracterizaremos essas publicações como "livros didáticos".

Souza (2014) nos lembra que o estudo de materiais didáticos pode ser um elemento importante na compreensão da história da educação musical e destaca os trabalhos de Souza (1997) e Silva (2002). Nessa direção, também encontramos o trabalho de Rocha (2013). O estudo aqui proposto diferenciase das pesquisas acima citadas por se centrar na compreensão da relação do professor não especialista em música com esse tipo de material. Considerando 2008 como um recorte, não encontramos algo similar nas edições deste ano e nas subsequentes da Revista da Associação Brasileira de Educação Musical (ABEM). ${ }^{6}$

Dentre os nossos procedimentos metodológicos, foi previsto um estudo junto a estudantes de pedagogia, que deveriam se apropriar desse material para o planejamento de atividades musicais a serem desenvolvidas em turmas da educação infantil. No presente texto, apresentamos reflexões a partir de uma primeira experiência de intervenção. Buscamos utilizar os livros didáticos como um mote para o planejamento de atividades, observando a sua legibilidade para o professor não especialista e as formas como ele faz uso deste material. Tendo sido esse o ponto de partida de uma experiência com o ensino de música na educação infantil, foi interessante notar a presença de desafios não previstos no planejamento das atividades. Em diversos momentos, vivenciamos aquilo que podemos referenciar como uma catástrofe! $^{7}$ O projeto foi realizado junto a quatro estudantes do curso de pedagogia do Instituto de Educação de Angra dos Reis (IEAR/UFF) e a duas turmas de educação infantil da Escola Municipal Cornelis Verolme, também situada na cidade de Angra dos Reis, no bairro de Jacuecanga.

\footnotetext{
${ }^{6}$ Tomamos esse ano como um recorte por considerar a possibilidade de um incremento nas publicações com este fim a partir da promulgação da Lei no 11.769 , de agosto de 2008 , que previa a obrigatoriedade do ensino de música em toda a educação básica. Vale observar que ela foi substituída pela Lei no 13.278 (Brasil, 2016), que inclui também como disciplinas obrigatórias a dança, o teatro e as artes visuais.

${ }^{7}$ A inspiração para o uso do termo catástrofe! veio da coleção As catástrofes de Gaspar e Lisa, da escritora francesa Anne Gutman, publicada pela editora Cosac Naify. São histórias curtas nas quais "a dupla de cachorros Gaspar e Lisa estimula as crianças a superarem os seus medos e provoca a criatividade para que encontrem a solução de problemas do cotidiano de qualquer família" (Gutman, 2010).
} 


\section{PRELIMINARES}

No início do ano de 2017, estávamos finalizando uma fase importante de nossas pesquisas sobre a música nas escolas públicas da Costa Verde Sul Fluminense. Em um período de aproximadamente seis anos, buscamos conhecer os impactos da Lei $\mathrm{n}^{\circ} 11.769$ nas escolas de quatro municípios vizinhos. Nesse período, obtivemos resultados similares a pesquisas realizadas em outras regiões do país. ${ }^{8}$ Observamos uma simultaneidade de visões sobre o papel da música na escola, prevalecendo aquela voltada para o cumprimento do calendário de festividades, além da falta de professores especializados em ensino musical. Em tal contexto, buscamos desenvolver, junto às secretarias municipais, escolas e professores, ações que pudessem contribuir para uma compreensão mais aprofundada da educação musical e, ao mesmo tempo, obter subsídios para a oferta de formação continuada nessa área aos professores da rede. Como representantes de uma universidade pública, estávamos atendendo a um dos dispositivos do parecer do Conselho Nacional de Educação sobre as Diretrizes Nacionais para a Operacionalização do Ensino de Música na Educação Básica (Brasil, 2013). Segundo o documento, compete ao Ministério da Educação o estímulo à oferta de cursos de formação inicial e continuada na área do ensino de música para os sistemas de ensino e instituições educacionais públicas; o incentivo à realização de estudos e pesquisas nas temáticas de música e do ensino de música na educação básica; e o desenvolvimento de programas de formação de profissionais e projetos educativos musicais nas escolas de educação básica (parágrafo $4^{\circ}$, incisos III, IV e V). De forma específica, o parecer atribui às instituições formadoras de educação superior e de educação profissional a inclusão nos currículos dos cursos de pedagogia o ensino de música, visando ao atendimento aos estudantes da educação infantil e dos anos iniciais do ensino fundamental (parágrafo $3^{\circ}$, inciso III).

Desse processo resultaram oficinas e cursos de extensão destinados aos professores da educação infantil; um material audiovisual (livro/CD) auxiliar para a formação pedagógico-musical de professores não especialistas, distribuído a cerca de 700 professores da rede pública da costa verde sul fluminense (REQUIÃO, 2013b) ${ }^{9}$; e um curso na modalidade a distância, para atender de forma permanente os professores, em especial os que atuam em localidades mais afastadas ou nas inúmeras ilhas da região. Nesse período, o currículo do curso no qual atuamos foi contemplado com a disciplina Educação Musical: Conteúdo e Método, obrigatória ao cumprimento dos créditos necessários para a obtenção do título de graduação em pedagogia. ${ }^{10}$

\footnotetext{
${ }^{8}$ Como, por exemplo, a pesquisa de Wolffenbüttel (2017), realizada em escolas públicas municipais do Rio Grande do Sul.

${ }^{9}$ Incluindo os municípios de Angra dos Reis, Mangaratiba, Paraty e Rio Claro.

${ }^{10}$ Sobre o processo que implementou a disciplina no currículo do curso de pedagogia do IEAR, ver Requião (2015).
} 
Naquele momento, quando foi iniciado o primeiro semestre letivo de 2017, o grupo de estudantes que acompanhou este trabalho havia se formado ou estava em fase de conclusão de curso. Nosso grupo, na ocasião, se resumia à participação de uma técnica em assuntos educacionais e da monitora da disciplina de Educação Musical. Foi quando três alunos nos procuraram interessados em participar das pesquisas do grupo de estudos. Dessa procura, surgiu a oportunidade de realizarmos um projeto que envolvesse a participação de estudantes de pedagogia juntamente com professores da educação infantil da rede pública do municipio de Angra dos Reis em intervenções musicais desenvolvidas a partir da utilização de livros didáticos. Nossa ambição era que esse projeto pudesse participar do Programa Institucional de Bolsas de Iniciação à Docência (PIBID). Nesse sentido, a proposta teve como um de seus pressupostos a necessidade de estabelecer um vínculo entre os estudantes de pedagogia e as salas de aula da rede pública. ${ }^{11}$

\section{INTERVENÇÕES MUSICAIS - JUNHO DE 2017}

Os alunos Jéssica, Larissa e Daniel, além da monitora Bianca, formaram a equipe de trabalho. Jéssica não tinha nenhuma experiência prévia com música, Larissa já havia estudado instrumento de sopro e Daniel tocava violão. A monitora Bianca já estava nos periodos finais, tendo cursado as disciplinas Arte e Educação e Educação Musical: Conteúdo e Método, obrigatórias no currículo de pedagogia do Instituto de Educação de Angra dos Reis (IEAR). Não tive preocupação em relação à presença ou à ausência de algum tipo de formação musical na trajetória dos estudantes participantes do grupo por considerar que, em sua totalidade, encontramos professores não especialistas com uma variada gama de experiências musicais. ${ }^{12}$ Decidimos procurar a Escola Municipal Cornelis Verolme, vizinha do IEAR, e propor uma série de encontros com atividades musicais para os alunos da educação infantil. Tivemos o apoio da direção e das professoras Eva e Kelly, que atuam com as turmas no período da tarde e da manhã, respectivamente. ${ }^{13}$ Chamamos esses encontros de intervenções musicais.

Combinamos de realizar um projeto-piloto composto por um módulo de oito intervenções no decorrer de um mês, quatro em cada turma (em encontros semanais). Criamos trios compostos por um coordenador, um auxiliar e um relator das atividades. O coordenador foi o principal responsável pelo desenvolvimento destas. O auxiliar foi o seu "braço direito", atuando de várias formas: no controle do tempo; trabalhando com grupos, caso a

\footnotetext{
${ }^{11}$ Infelizmente não tivemos essa oportunidade, pois, na ocasião, o programa se encontrava em fase de retração. Sobre o PIBID, ver: <http://portal.mec.gov.br/pibid>.

12 Essa situação foi observada na pesquisa que realizamos em escolas públicas de quatro municípios da Costa Verde Sul Fluminense (Requião, 2013a).

13 De acordo com o depoimento das professoras, o trabalho com música limitava-se, na ocasião, ao acompanhamento da rotina escolar.
} 
atividade previsse a divisão da turma; auxiliando em algum evento não esperado etc. O relator teve a função de registrar as ações em todo o seu processo, em forma de texto, foto e/ou vídeo. Esse registro foi fundamental para os nossos encontros após cada intervenção, quando eram relatadas as impressões sobre o ocorrido.

Cada intervenção foi planejada para ter a duração de uma hora, conforme proposta das professoras regentes, sendo sempre iniciada após o recreio das turmas. Os encontros de supervisão se davam uma hora antes e imediatamente após cada intervenção. As equipes foram divididas de forma que os quatro estudantes (Jéssica, Larissa, Daniel e Bianca) tivessem um revezamento nas funções acima descritas. Minha atuação se limitou à organização das equipes e à oferta dos recursos e materiais necessários. Nos encontros de supervisão, minha função era registrar o relato e a avaliação dos estudantes. Era o momento de compreender as dificuldades e as soluções encontradas por eles, assim como a sua forma de conceber a música em relação à formação geral das crianças. Busquei intervir o menos possivel nas discussões, na seleção e no planejamento das atividades. Vale notar que não presenciei nenhum dos encontros na escola, e minhas impressões se deram a partir do relato dos alunos e de conversas com as professoras das turmas, em uma etapa posterior.

Foram selecionadas pelos estudantes três publicações de referência para esta etapa. ${ }^{14} \mathrm{Um}$ dos pontos de minha observação sobre a relação entre os professores não especialistas e os livros didáticos começou justamente por compreender os critérios que eles utilizam para selecionar os materiais. Nesse momento, a forma de apresentação do livro, o seu colorido e a facilidade no acesso às atividades (principalmente na forma de visualizá-las) foram aspectos fundamentais para atrair os estudantes.

Foram estas as publicações selecionadas:

\footnotetext{
${ }^{14}$ Utilizamos o material que foi adquirido por meio do projeto Implementação da Lei 11769: construção de uma proposta de formação inicial e continuada para professores da rede pública da Costa Verde Sul Fluminense na área da educação musical, contemplado com recursos da FAPERJ na modalidade APQ1. Na ocasião, fizemos uma busca na internet por materiais voltados para o ensino de música e que fossem destinados ao professor não especialista. Nosso acervo conta com cerca de vinte materiais impressos desse tipo.
} 


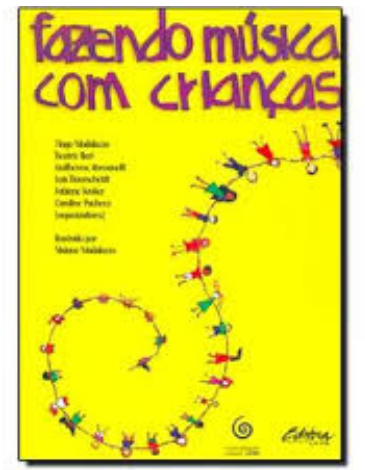

Figura 1: Fazendo música com crianças (Nicolau et al., 2011).

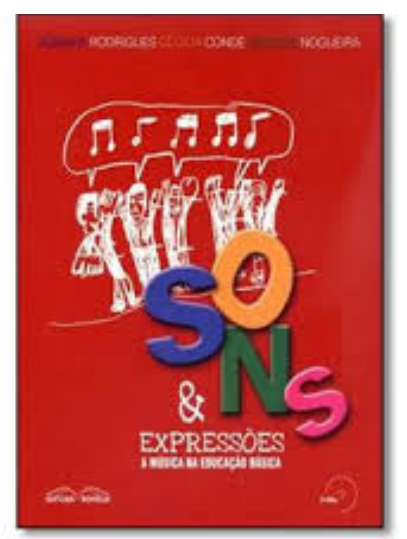

Figura 2: Sons e expressões: a música na educação básica (Rodrigues; Conde; Nogueira, 2013).

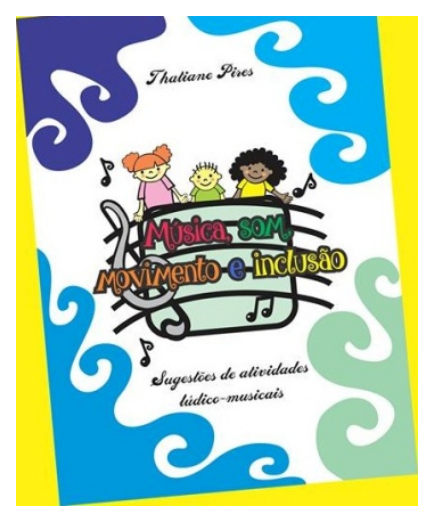

Figura 3: Música, som, movimento e inclusão: sugestões de atividades lúdico-musicais (Pires, 2016).

De forma geral, as propostas de atividades contidas nos materiais consultados dão ênfase a algum elemento sonoro-musical (como o timbre, a altura, a duração, a intensidade, o pulso, a forma etc.). No manuseio do material, foi selecionada uma série de atividades que pareceram atraentes ou factiveis aos alunos. Isso se deu, em grande parte, pela compreensão que eles tiveram das etapas previstas nos livros didáticos. Em alguns casos, os autores das publicações utilizam termos pouco conhecidos por professores não 
especialistas, como compasso e timbre, por exemplo, e, muitas vezes, usam um glossário para a consulta. Textos mais diretos, que dispensam qualquer recurso para a sua compreensão, tiveram uma melhor aceitação por parte desse grupo de estudantes.

Após selecionar os livros didáticos, o grupo elaborou um plano para cada intervenção que englobaria um conjunto de atividades. Pedi que me entregassem o plano por escrito, mas sempre o que recebi foram anotações muito resumidas, uma espécie de roteiro indicando ou lembrando a eles o combinado. O que transcrevo abaixo é a tradução de um desses planos que fiz a partir das anotações dos alunos e das discussões prévias, antes de entrarem em sala de aula.

\section{Atividade planejada:}

1. Ritual de chegada e de boas-vindas aos alunos: o trio condutor da atividade se apresentará e cada aluno da turma falará o seu nome. Para esse momento, foi sugerida pela aluna Bianca uma música para a acolhida do grupo. ${ }^{15}$

2. Venda nos olhos: de onde vem o som? A atividade consistirá em duas crianças irem para o centro da roda formada pelos outros alunos da turma. Elas estarão com os olhos vendados e deverão identificar de onde vem o som produzido por outro aluno em algum ponto da roda. Quem indicará o aluno que irá produzir o som é o coordenador da atividade.

3. Passeio pelo pátio da escola: as crianças serão instigadas a observar os sons que compõem a paisagem sonora do pátio da escola. Estarão os sons perto? Longe? Em movimento?

4. Regendo os sons: cada criança deverá escolher um som a partir do seu corpo, podendo também usar a voz. Uma delas será a regente e ficará no centro da roda, determinando a ordem de entrada/saída de cada som. Teremos assim uma orquestra que resultará em variadas sonoridades. Todos serão convidados a serem o regente.

5. Ritual de despedida: todos sentarão em roda, escutarão e cantarão a mesma canção utilizada no ritual de boas-vindas.

Materiais necessários: duas vendas de olhos

\footnotetext{
15 A música é parte de um canal do YouTube intitulado "Turminha do Tio Marcelo". Disponível em: <https://www.youtube.com/watch?v=g-Cmx_1-oXs\&list=TLZW-E83YqRNXf5F4gmZeL71eu9nTTVNqt>. Acesso em: 28 fev. 2018.
} 


\section{Referências principais:}

Rodrigues, Conde e Nogueira (2013, p. 72-73) - Atributos básicos do som: fontes, ondas e imagens sonoras; e Schafer (2011, p. 55-106) - Limpeza de ouvidos. ${ }^{16}$

Como forma de avaliar o trabalho realizado, foi sugerido pelo grupo um roteiro de observação, uma espécie de questionário a ser respondido por eles mesmos, após cada intervenção. Para a atividade acima, foram elaborados os seguintes itens de observação:

\section{Roteiro de observação:}

1. O grupo de alunos interagiu entre si e com a equipe?

2. Os alunos conseguiram perceber a origem dos sons?

3. Os alunos conseguiram perceber os sons em perspectiva (perto/longe)?

4. Os alunos atentaram para os diferentes sons que compõem uma paisagem sonora?

5. Os alunos conseguiram se sentir à vontade ao explorarem possibilidades sonoras a partir de vocalizações ou percussão corporal?

6. Os alunos buscaram explorar texturas diferenciadas ao reger o grupo?

Essa foi a primeira atividade proposta pelo grupo e, ao regressarem da escola, em nosso encontro após a intervenção, perguntei: "E então, como foi?". Tive como resposta algo como: "Uma catástrofe!". A experiência em sala de aula foi mais desafiadora do que poderia parecer aos estudantes. As situações se mostraram incertas e imprevisiveis, permeadas de desvios, riscos e situações de catástrofe! Ao mesmo tempo em que os estudantes mostraram ter tido empatia com as crianças e com a professora, estavam também bastante inquietos por terem sentido "perder o controle" da situação. De forma geral, eles observaram que as atividades propostas eram individuais, um aluno por vez, o que para crianças entre quatro e cinco anos de idade pareceu não funcionar. Mesmo com o auxílio da professora regente, que permaneceu em sala de aula, não foi possivel conter a animação da criançada, que deveria esperar "a sua vez" de participar da atividade. Nas palavras Jéssica, uma das participantes de nosso grupo:

Já de início, percebi que a turma era muito dispersa. No jogo da venda, as crianças estavam comportadas, mas não ficavam

\footnotetext{
${ }^{16}$ A leitura de Schafer foi sugerida pela monitora Bianca. A estudante já conhecia este texto por conta da disciplina cursada Educação Musical: Conteúdo e Método.
} 
em roda direito, ficavam mais espalhadas ou sentadas, embora parecessem estar gostando da brincadeira. Tinha uma criança que não ficava parada, queria sempre brincar com algo, mexer em algo. Percebemos isso quando sentamos em roda para conversar sobre os sons da sala ou de algum outro cenário, para ver se estava perto ou longe. Como ficou muito abstrato, as crianças não queriam muito conversar, pois, em minha opinião, elas achavam que aquilo era mais uma aula e queriam brincar. As crianças, a toda hora, começavam a brincar.

Um problema grande dessa turma é que eles não ficam quietos/em silêncio. Então, durante a brincadeira, muitos alunos faziam o som quando não era a vez deles, e os outros amiguinhos também os imitavam, gerando uma bagunça que os professores até conseguiam resolver, mas que atrapalhava a outra criança a adivinhar de onde vinha o som. Depois que acabou essa atividade, fomos para fora da sala ouvir os sons da rua, o que, por um lado, funcionou, porque os deixou mais focados, mas também tinha o recreio de outra turma, que tornou tudo mais complicado. No geral, a aula foi boa, mas poderia conter mais atividades menos abstratas para prender a atenção das crianças.

Grosso modo, os relatos individuais apontaram três pontos importantes que seriam discutidos e levados em consideração nos planejamentos seguintes: (1) a necessidade de atividades coletivas e de curta duração; (2) a apresentação de propostas claras que não gerassem dúvidas ou a possibilidade de má interpretação pelas crianças; (3) a importância do jogo e da brincadeira. Porém, nas entrelinhas, os estudantes deixavam escapar elementos interessantes para a nossa investigação. O roteiro planejado para a aula pareceu demasiadamente engessado, e eles não conseguiram gerar alternativas para as atividades propostas. A interferência das crianças gerou, na maioria das vezes, desconforto e foi compreendida como algo fora do padrão de comportamento esperado. Se esses fatos ocorriam, eram considerados pelo grupo como uma espécie de catástrofe, algo que tiraria um suposto controle da aula das mãos do professor. Por outro lado, entendo que, tal qual na história de Gutman (2010), esses eventos serviriam também para superar o "medo" e provocar a criatividade. Foram exatamente essas catástrofes que nos levaram a um segundo momento, após a série de intervenções planejadas. Entendemos a necessidade de discutir a experiência a partir de um estudo bibliográfico que nos apoiasse na compreensão dos propósitos e dos meios necessários para o desenvolvimento de um trabalho musical na educação infantil.

\section{DISCUTINDO A EXPERIÊNCIA}

A despeito do objetivo inicial sobre a análise do livro didático, conforme exposto anteriormente, as intervenções realizadas trouxeram como tônica 
para as nossas discussões a necessidade de pensar nessas situações que chamamos de catástrofes. Tomamos como referência a noção de reflexão em ação, conforme encontrada em Schön (2000). Partindo da noção do que o autor chama de zonas indeterminadas da prática - certas situações de incerteza e de singularidade com que os profissionais se deparam -, Schön defende a ideia de um ensino prático reflexivo no qual os estudantes aprendem principalmente através do fazer, apoiados pela instrução" (p. viii). Fomos ao encontro de duas importantes questões por ele observadas: "As coisas mais importantes não podem ser ensinadas, mas devem ser descobertas e apropriadas pela própria pessoa" (p. 78); e "o professor não ensina, mas serve como um provocador e um parteiro da autodescoberta de outros" (p. 78).

A partir da provocação causada pela experiência em sala de aula, o grupo se propôs a conhecer e a discutir trabalhos de educadores musicais que tratassem do ensino de música na educação infantil ou nas séries iniciais do ensino fundamental. Como proposta de trabalho, realizamos uma busca bibliográfica na Revista da ABEM com o intuito de selecionar alguns artigos. ${ }^{17}$ Essa busca foi feita pelos estudantes que selecionaram cinco artigos para o nosso estudo, a saber: "Ensino musical criativo em atividades de composição na escola básica" (Beineke, 2015), "As crianças pequenas e seus processos de apropriação da música" (Schroeder; Schroeder, 2011), "Música e histórias infantis: o engajamento da criança de 0 a 4 anos nas aulas de música" (Schünemann; Maffioletti, 2011), "Barulhar: a música das culturas infantis" (Lino, 2010) e "Ferramentas com brinquedos: a caixa da música" (Brito, 2010). A partir da leitura dos textos, levantamos alguns principios que consideramos importantes para nortear o nosso trabalho futuro de pesquisa e de intervenção.

Discorrendo sobre uma proposta de trabalho criativo em sala de aula, Beineke (2015) mostra a necessidade por parte do professor de perceber como as crianças se engajam nas atividades propostas. Assim como Schön, a autora observa que o professor que tem capacidade de refletir sobre o que acontece em aula poderá ajustar a sua pedagogia, redimensionando o trabalho sempre que necessário. Sua observação revela a importância de um ambiente de trabalho colaborativo "em que as crianças se sentem seguras para expressar as suas ideias, o que parece ser um reflexo da valorização e do respeito da professora pelos seus modos de fazer e pensar música" (p. 54).

Schroeder e Schroeder (2011) discutem os processos de apropriação da música por crianças em idade pré-escolar. A partir deste trabalho, o nosso grupo de estudo elencou questões importantes levantadas pelos autores, sendo a consideração da música como uma forma de discurso um dos pontos centrais da discussão.

A noção de discurso obriga a um deslocamento do ensino, antes centrado em objetos, em direção às práticas. Se a

\footnotetext{
${ }^{17}$ Ver em: <http://abemeducacaomusical.com.br/revistas/revistaabem/index.php/revistaabem/index>.
} 
música é um acontecimento vivo, uma forma de compartilhar sentidos, aprender música não é dominar regras e sistemas, mas ser inserido na "corrente da comunicação musical", ser capaz de fazer um uso pessoal, autoral, próprio, dos sistemas e regras musicais (que obviamente existem, mas não constituem a totalidade da linguagem musical) (Schroeder; Schroeder, 2011, p. 116).

Esse foi o mote para discutirmos a música não só na educação básica, como também na própria formação dos professores-pedagogos. Foi importante observar que, de acordo com os autores, "o processo de apropriação [musical] não se mostra regular, nem contínuo e nem mesmo homogêneo" (Schroeder; Schroeder, 2011, p. 116). ${ }^{18}$ Eles destacam ainda a importância da integração da música com outras linguagens no contexto da educação infantil, pois "incluir essas outras formas de expressão não é apenas um recurso para tornar mais prazerosa a aula, mas uma necessidade real, quando se leva em conta tanto as especificidades da música quanto o desenvolvimento infantil" (Schroeder; Schroeder, 2011, p. 17). Corroborando esta última ideia, Schünemann e Maffioletti (2011, p. 129) mostram a importância de trabalhar com histórias no âmbito da educação infantil.

Foi observado que a articulação entre a música e a história promove, de modo mais intenso, o interesse das crianças nos momentos em que surge algum personagem ou a utilização de fantoches, os instrumentos musicais, as movimentações do corpo, as figuras coloridas, os timbres diferentes das vozes.

Lino (2010, p. 86) nos traz a noção de barulhar infantil, "um processo de transbordamento conquistado sempre que elas [as crianças] têm liberdade para brincar com sons e/ou encontrar provisoriamente espaços de indeterminação, imprevisibilidade e não linearidade no contexto escolar". Novamente, esta ideia nos remete a Schön, na medida em que somente um(a) professor(a) reflexivo(a) teria condições de atuar em um contexto como este sem correr o risco "de manter-se estática e petrificada pelas rotinas sonoras oferecidas no cardápio escolar que não tem acolhido o imprevisto e o impreciso característicos da expressão sonora na infância” (Lino, 2010, p. 86). Indo nessa mesma direção, um elenco de questões a serem observadas em

\footnotetext{
18 “Em outras palavras, as crianças deram vários indícios de que esses processos sofrem muitas regressões, além das progressões; não se dão em grau igual de facilidade ou dificuldade em todos os âmbitos musicais (ritmo, afinação, memória etc.); não mantêm um ritmo de progresso constante e gradual, mas se movimentam, às vezes, bruscamente, por saltos, em degraus de dificuldade, outras vezes, em lenta progressão e, outras vezes ainda, estacionam por algum tempo. Com frequência, algumas crianças mostram uma regularidade temporal em certas atividades e um total descontrole rítmico em outras; algumas se mostram afinadas em certas músicas e desafinadas em outras, ou afinadas em certas execuções e desafinadas em outras, da mesma música; algumas compreendem bem as propostas. mas as executam de forma alterada ("erros"), outra executam "certinho" as propostas, porém, em lapsos momentâneos, indicam uma total ignorância sobre o significado do que estão executando. A entrada das crianças no fluxo discursivo, na cadeia de enunciados musicais, não se dá de uma vez e nem definitivamente. Ela tem altos e baixos, vaivéns, acontece e desaparece como que por encanto e depois retorna" (Schroeder; Schroeder, 2011, p. 116).
} 
um projeto de ensino musical é apontado por Brito (2010, p. 93), do qual destacamos a necessidade de "uma organização curricular aberta à emergência de acontecimentos, de interesses e propostas; atenta ao ramificar. Currículo não prescrito, mas atualizado dinamicamente". ${ }^{19}$

Resumidamente, a partir da leitura dos textos, definimos, como fundamentais para o desenvolvimento de um trabalho com música no âmbito da educação infantil, os seguintes pontos:

- o redimensionamento do trabalho sempre que necessário;

- a promoção de um ambiente de trabalho colaborativo;

- a consideração da música como uma forma de discurso;

- a integração da música com outras linguagens;

- o trabalho com histórias;

- a promoção de um ambiente de liberdade para o brincar com sons;

- o acolhimento do imprevisto e do impreciso, características da expressão sonora na infância;

- o estabelecimento de uma organização curricular aberta à emergência de acontecimentos, de interesses e de propostas.

As discussões promovidas pelo grupo de estudos a partir desses textos instigaram ainda mais nos alunos a vontade de ir a campo, de adentrar em uma sala de aula de educação infantil e de iniciar o trabalho com a música. Nesse ponto, observamos a necessidade para o professor-pedagogo de uma formação musical que inclua não somente a formação inicial, quando ela existir, mas também uma busca continuada e pautada na experiência. ${ }^{20}$

De forma geral, percebi que os livros didáticos que utilizamos não são suficientes como um material de trabalho para o professor não especialista. As atividades possiveis de serem desenvolvidas sem uma formação específica são limitadas por uma compreensão bastante superficial do que pode ser um trabalho com música em sala de aula. A tendência é um apego exagerado aos procedimentos descritos nos livros e pouca liberdade para se arriscar em novas interpretações e interações não previstas. Como a imprevisibilidade foi

\footnotetext{
${ }^{19}$ Os outros pontos, não menos importantes, a serem considerados são: “• O dinamismo das 'ideias de música' que se reelaboram continuamente; o modo emergente e dinâmico de perceber, conscientizar e fazer música no curso da vida, da infância à maturidade. • A integração entre o gesto/a ação/a escuta/o pensamento musical; entre a prática e a reflexão; entre o corpo e a mente. • A superação de pensamentos/ações dualistas. • A criação como uma ferramenta essencial ao desenvolvimento musical e humano. $\bullet$ O equilíbrio entre os aspectos e os conceitos quantitativos (de ordem estrutural, da objetividade) e qualitativos (de ordem sensível, da subjetividade), considerando que, acima de tudo, fazer música é produzir qualidades. • A diversidade, a exploração e a pesquisa; o "brincar"; o contato com as "muitas músicas da música". • O relacionamento da música com as demais áreas do conhecimento e, mais do que isso, com o viver. $\bullet 0$ direito do aluno à coautoria de seu processo de construção do conhecimento musical. - A resistência ao padrão, em nome da busca de singularidade, de sentido e de significado. • O humano como o objetivo maior da educação musical" (Brito, 2010, p. 93).

${ }^{20}$ Experiência entendida aqui conforme Bondía (2002, p. 21), como aquilo "que nos passa, o que nos acontece, o que nos toca".
} 
a tônica da experiência relatada, a pouca familiaridade com conhecimentos musicais e com questões intrínsecas ao ambiente da educação infantil, além de um pensamento pouco abrangente sobre a música, foram barreiras que os estudantes tiveram dificuldade de superar para dar conta dos pontos que eles mesmos elencaram como fundamentais, como, por exemplo, o redimensionamento do trabalho pelo acolhimento do imprevisto e do impreciso.

Contudo, a experiência de trabalhar com um grupo de alunos, a partir de suas experiências prévias com a música, quaisquer que fossem elas, e de inseri-los no ambiente da educação infantil para que pudessem compreender in loco os desafios que teriam que enfrentar em suas vidas profissionais foi desafiadora e essencial para as reflexões aqui desenvolvidas. Tal experiência foi ainda importante para a minha prática pedagógica, para uma melhor compreensão sobre os saberes musicais e pedagógico-musicais necessários à atuação de professores regentes na educação infantil, objetivo que venho perseguindo desde que me vi como professora de música responsável pela formação de professores-pedagogos. Essa experiência pareceu corresponder aos objetivos centrais da pesquisa, que são compreender e discutir o papel da arte na educação infantil e como a formação acadêmica e a atuação de professores-pedagogos podem favorecer o desenvolvimento da arte nesse âmbito escolar. Assim, mais do que buscar capacitar os futuros pedagogos no manejo com os elementos musicais, ficou latente a necessidade de conjugar esses saberes com a dinâmica de ensino necessária e as especificidades do campo de atuação do professor regente de turma.

Em nosso caso específico, entendemos que, na proposta curricular do curso de pedagogia do IEAR, disciplinas como Arte e Educação, Educação Musical: Conteúdo e Método, Educação Infantil, Psicologia da Educação e outras devem ter as suas fronteiras diluidas e as suas abordagens articuladas. Nesse sentido, entendemos que uma discussão em torno da interdisciplinaridade se faz premente. Está aí o nosso grande desafio. Apesar de a interdisciplinaridade ser contemplada na legislação vigente, como, por exemplo, nas Diretrizes Curriculares Nacionais para o Curso de Graduação em Pedagogia (Brasil, 2006), Figueiredo (2017, p. 93) mostra que

[...] a hegemonia dos modelos disciplinares não parece compativel com as propostas interdisciplinares, o que significa que há certa contradição entre a lei e a prática da lei. A ênfase na disciplinaridade vem historicamente ocupando um espaço predominante, o que significa que a adoção da interdisciplinaridade depende de mudanças sistemáticas e profundas nos processos de formação universitária, o que inclui a revisão de modelos e também a formação do quadro docente para a atuação na perspectiva interdisciplinar.

As reflexões que a experiência relatada nos proporcionou sugerem que a arte, mesmo em sua condição de disciplina curricular, pode colaborar para 
um processo interdisciplinar de formação de professores. Entendemos ser este um trabalho necessário e relevante para a formação de professorespedagogos.

\section{REFERENCIAS}

BEINEKE, Viviane. Ensino musical criativo em atividades de composição na escola básica. Revista da ABEM, Londrina, v. 23, p. 42-57, jan./jun. 2015.

BELLOCHIO, Cláudia R.; GARBOSA, Luciane W. F. (Orgs.). Educação musical e pedagogia: pesquisas, escutas e ações. Campinas: Mercado de Letras, 2014.

BONDÍA, Jorge L. Notas sobre a experiência e o saber da experiência. Revista Brasileira de Educação, n. 19, p. 20-28, jan./fev./mar./abr. 2002. Disponivel em: <http://www.scielo.br/pdf/rbedu/n19/n19a02.pdf>. Acesso em: 21 set. 2017.

BRASIL. Lei $\mathrm{n}^{\circ}$ 13.278, de 2 de maio de 2016. Altera o § 6o do art. 26 da Lei no 9.394, de 20 de dezembro de 1996, que fixa as diretrizes e bases da educação nacional, referente ao ensino da arte. Diário Oficial da União, Brasília, seção 1, p. 1, 3 maio 2016. Disponível em: <http://www.planalto.gov.br/ccivil_03/_ato20152018/2016/lei/113278.htm>. Acesso em: 28 fev. 2018.

Conselho Nacional de Educação. Diretrizes Nacionais para a Operacionalização do Ensino de Música na Educação Básica. Parecer CNE/CEB n. 12/2013. Disponível em: <http://portal.mec.gov.br>. Acesso em: 11 fev. 2016.

. Lei $\mathrm{n}^{\circ} 11.769$, de 18 de agosto de 2008. Altera a Lei $\mathrm{n}^{\circ} 9.394$, de 20 de dezembro de 1996, para dispor sobre a obrigatoriedade do ensino da música na educação básica. Diário Oficial da União, Brasília, ano CXLV, n. 159, seção 1, p. 1, 19 ago. 2008. Disponivel em: <http://www2.camara.leg.br/legin/fed/lei/2008/lei-11769-18-agosto2008-579455-publicacaooriginal-102349-pl.html>. Acesso em: 28 fev. 2018.

Ministério da Educação. Resolução CNE/CP n. 1, de 15 de maio de 2006. Institui Diretrizes Curriculares Nacionais para o Curso de Graduação em Pedagogia, licenciatura. Brasília, DF, 2006. Disponível em: <http://portal.mec.gov.br/cne/arquivos/pdf/rcp01_06.pdf>. Acesso em: 1 mar. 2018.

BRITO, Teca A. de. Ferramentas com brinquedos: a caixa da música. Revista da ABEM, Porto Alegre, v. 24, p. 89-93, set. 2010.

FIGUEIREDO, Sérgio. A música e as artes na formação do pedagogo: polivalência ou interdisciplinaridade. Revista da FAEEBA - Educação e Contemporaneidade, Salvador, v. 26, n. 48, p. 79-96, jan./abr. 2017. 
. O processo de aprovação da Lei 11.769/2008 e a obrigatoriedade da música na Educação Básica. In: ENDIPE - ENCONTRO NACIONAL DE DIDÁTICA E PRÁTICA DE ENSINO - CONVERGÊNCIAS E TENSÕES NO CAMPO DA FORMAÇÃO E DO TRABALHO DOCENTE, 15., 2010, Belo Horizonte. Anais... Belo Horizonte, 2010. Painel.

GUTMAN, Anne. Os pesadelos de Lisa. São Paulo: Cosac Naify, 2010.

LINO, Dulcimarta L. Barulhar: a música das culturas infantis. Revista da ABEM, Porto Alegre, v. 24, p. 81-88, set. 2010

NICOLAU, Amanda C. R. et al. Fazendo música com crianças. Curitiba: UFPR, 2011.

PEREIRA, Luis F. R. Um movimento na história da educação musical no Brasil: uma análise da campanha pela Lei 11.769/2008. Dissertação (Mestrado em Música) - Programa de Pós-Graduação em Música, Centro de Letras e Artes, Universidade Federal do Estado do Rio de Janeiro, Rio de Janeiro, 2010.

PIRES, Thatiane. Música, som, movimento e inclusão: sugestões de atividades lúdico-musicais. Niterói: Edição do autor, 2016.

REQUIÃO, Luciana. A educação musical em sala de aula e a música na formação do professor unidocente: uma experiência com estudantes de pedagogia do Instituto de Educação de Angra dos Reis. In: RIBEIRO, William de G. (Org.). Práticas pedagógicas, currículo e formação docente: tecendo reflexões em educação. Curitiba: CRV, 2017. p. 101-113.

. Apenas a lei não basta: o processo de implementação da educação musical em um curso de pedagogia do litoral sul fluminense. In: CONGRESSO NACIONAL DA ASSOCIAÇÃO BRASILEIRA DE EDUCAÇÃO MUSICAL, 22., 2015, Natal. Anais... 2015. Disponivel em: <http://abemeducacaomusical.com.br/conferencias/index.php/xxiicongres so/xxiicongresso/paper/viewFile/1049/502>. Acesso em: 27 fev. 2018.

. Educação musical em escolas da Costa Verde Sul Fluminense: problematizando possibilidades de implementação da Lei 11.769/2008. Revista da ABEM, Londrina, v. 21, p. 91-102, 2013 a.

Sons e pulso: formação inicial em música e educação. Rio de Janeiro: Edição do autor, 2013b.

ROCHA, Suzana de O. F. Música na escola particular de educação básica: considerações sobre o livro didático de música e a atuação do educador musical. Dissertação (Mestrado em Música) - Universidade Federal de Goiás, Goiânia, 2013.

RODRIGUES, Adriana; CONDE, Cecilia; NOGUEIRA, Marcos. Sons e expressões: a música na educação básica. Rio de Janeiro: Rovelle, 2013. 
SCHAFER, Murray. O ouvido pensante. São Paulo: UNESP, 2011.

SCHÖN, Donald A. Educando o profissional reflexivo: um novo design para o ensino e a aprendizagem. Porto Alegre: Artmed, 2000.

SCHROEDER, Sílvia C. N.; SCHROEDER, Jorge L. As crianças pequenas e seus processos de apropriação da música. Revista da $A B E M$, Londrina, v. 19, p. 105-118, jul./dez. 2011.

SCHÜNEMANN, Aneliese T.; MAFFIOLETTI, Leda de A. Música e histórias infantis: o engajamento da criança de 0 a 4 anos nas aulas de música. Revista da ABEM, Londrina, v. 19, p. 119-131, jul./dez. 2011.

SILVA, Nisiane F. da. A representação de música brasileira nos livros didáticos de música. Dissertação (Mestrado em Música) - Universidade Federal do Rio Grande do Sul, Porto Alegre, 2002.

SILVA, Everson M. A.; ARAÚJO, Clarissa M. de. Tendências e concepções do ensino de arte na educação escolar brasileira: um estudo a partir da trajetória histórica e socioepistemológica da arte/educação. In: REUNIÃO DA ANPED, 30., 2007, Caxambu. Anais... Caxambu, 2007. Disponivel em: <http://30reuniao.anped.org.br/grupo_estudos/GE01-3073--Int.pdf>. Acesso em: 27 fev. 2018.

SOUZA, Jusamara. Sobre as várias histórias da educação musical no Brasil. Revista da ABEM, Londrina, v. 22, p. 109-120, jul./dez. 2014.

(Org.). Livros de música para a escola: uma bibliografia comentada. Série Estudos, n. 3. Porto Alegre: PPG Música UFRGS, 1997.

WOLFFENBÜTTEL, Cristina R. Música nas escolas públicas municipais do Rio Grande do Sul. Revista Brasileira de Educação, Rio de Janeiro, v. 22, n. 71, 2017. Disponivel em:

<http:/ / www.scielo.br/scielo.php?script=sci_arttext\&pid=S1413-

24782017000400236\&lng=pt\&tlng=pt>. Acesso em: 27 fev. 2018. 
Luciana Requião é professora do Departamento de Educação da Universidade Federal Fluminense (UFF). É Doutora em Educação (2008) pela Universidade Federal Fluminense, onde também desenvolveu pesquisa de pós-doutorado (2009), Mestre em Música (2002) e Graduada no curso de Licenciatura em Educação Artística (1999) pela Universidade Federal do Estado do Rio de Janeiro. Tem experiência na área de Artes e de Educação, com ênfase em Música, atuando principalmente nos seguintes temas: formação, processos e relações de trabalho do músico popular; Ensino e Aprendizagem das Práticas Musicais no âmbito da música popular e o trabalho do Músico-Professor; Arte, Educação Musical e a Formação do Pedagogo; Mundo do Trabalho, Música e Cultura no Capitalismo Tardio. É professora associada da Universidade Federal Fluminense, lotada no Instituto de Educação de Angra dos Reis, e membro permanente do Programa de Pós Graduação em Música da UNIRIO (PPGM) e do Programa de Mestrado Profissional em Ensino das Práticas Musicais da UNIRIO (PROEMUS). É lider do Grupo de Estudos em Cultura, Trabalho e Educação (GECULTE) e autora dos livros O Músico-Professor (2002), Eis aí a Lapa...: processos e relações de trabalho do músico nas casas de shows da Lapa (2010) e Sons e Pulso: formação inicial em música e educação (2013). Atualmente faz estágio de pós-doutorado junto ao Laboratório de Etnomusicologia da UFRJ. 